\title{
BMJ Open Proactive telephone-based peer support for breastfeeding: a cross-sectional survey of women's experiences of receiving support in the RUBY randomised controlled trial
}

\author{
Fiona E McLardie-Hore (D) ,,2 Helen L McLachlan (D) ,2,3 Touran Shafiei (D) , \\ Della A Forster (1) 1,2
}

To cite: McLardie-Hore FE, McLachlan HL, Shafiei T, et al. Proactive telephonebased peer support for breastfeeding: a crosssectional survey of women's experiences of receiving support in the RUBY randomised controlled trial. BMJ Open 2020;10:e040412. doi:10.1136/ bmjopen-2020-040412

- Prepublication history and additional material for this paper is available online. To view these files, please visit the journal online (http://dx.doi.org/10. 1136/bmjopen-2020-040412)

Received 13 May 2020 Revised 14 September 2020 Accepted 23 September 2020

D) Check for updates

(c) Author(s) (or their employer(s)) 2020. Re-use permitted under CC BY-NC. No commercial re-use. See rights and permissions. Published by BMJ.

${ }^{1}$ Midwifery and Maternity Services Research, Royal Women's Hospital, Parkville, Victoria, Australia

${ }^{2}$ Judith Lumley Centre, La Trobe University, Bundoora, Victoria, Australia

${ }^{3}$ School of Nursing and Midwifery, La Trobe University, Bundoora, Victoria, Australia

Correspondence to Fiona E McLardie-Hore; Fiona.McLardieHore@ thewomens.org.au

\section{ABSTRACT}

Objective The Ringing Up about Breastfeeding earlY (RUBY) randomised controlled trial (RCT) of proactive telephonebased peer support for breastfeeding found that infants of women allocated to the intervention were more likely to be receiving breast milk at 6 months of age than those receiving usual care. This study explores women's experiences of receiving the RUBY peer support intervention.

Design Cross-sectional survey.

Setting Women were recruited from the postnatal units of three tertiary hospitals in Melbourne, Australia.

Participants Women allocated to receive telephone peer support in the RUBY RCT who completed a telephone interview at 6 months postpartum (501/574 (87\%) in trial intervention arm) were invited to complete a postal survey on their experience of receiving support.

Outcomes Experiences of support from the allocated peer, perceived helpfulness, topics discussed, overall satisfaction with the support and frequency and duration of contact were explored.

Results Surveys were sent between August 2013 and March 2016, and 72\% (360/501) responded of whom 341 recalled receiving peer support. Women reported high levels of perceived helpfulness $(79 \%)$ and overall satisfaction with the peer support (93\%). Discussions included breastfeeding topics (milk supply, attachment), baby care, baby behaviour, and reassurance and emotional support. Women valued the practical and realistic support from another mother, as well as the proactive nature, continuity and accessibility of the support. The empathy, reassurance and encouragement provided helped the mothers to 'cope', to continue breast feeding and to feel empowered.

Conclusion Most respondents were positive about their experience of receiving proactive telephone peer support for breastfeeding, further supporting the roll-out of this model as a strategy for increasing breastfeeding maintenance to 6 months. Recommendations include flexibility in the scheduling of calls according to individual need, and the use of text messages in conjunction with proactive calls, to enhance and facilitate communication between the peer and the mother.

Trial registration number ACTRN12612001024831.
Strengths and limitations of this study

- The study was conducted as part of a large systematically conducted randomised controlled trial, increasing the study rigour.

- Qualitative data have been used to support and enhance understanding of quantitative data.

- The use of a validated tool, Peer Support Evaluation Inventory (PSEI) to explore mother's experiences strengthens this study.

- The study was restricted to primiparous women, from metropolitan Melbourne, Australia.

- The PSEI Tool was added to the survey after the first 207 surveys had been distributed, resulting in fewer responses to this section.

\section{INTRODUCTION}

\section{Background}

Despite the significant health and economic benefits of breastfeeding, ${ }^{1}{ }^{2}$ effective strategies to increase breastfeeding maintenance in high-income countries have proven complex. Breastfeeding duration in most high-income countries remains shorter compared with lowincome countries ${ }^{2}$ and shorter than WHO recommendations. ${ }^{3}$ Increasing the rates of breastfeeding worldwide is fundamental to achieving the United Nations Sustainable Development Goals by 2030. ${ }^{4}$ The most recent Cochrane review on support for healthy breastfeeding mothers and healthy term babies found evidence of the value of face-to-face support from health professionals to increase breastfeeding $;{ }^{5}$ however, this is an expensive option at a population level, particularly if the intervention needs to be maintained for up to 6 months postpartum. Programmes of peer support for breastfeeding, while less costly than professional support, have varied greatly in their timing, 
mode of delivery and length of support, producing mixed results, with the more effective programmes being in lowincome settings. ${ }^{5}$

Telephone peer support is another potentially effective, sustainable and cost-effective intervention; however, the Cochrane review found no association between (predominantly) telephone peer support and increased breastfeeding maintenance. ${ }^{5}$ Since that review, a large Australian randomised controlled trial (RCT) of 1152 women 'Ringing up about breastfeeding early' (RUBY) found a positive association between receiving proactive (volunteer) peer support by telephone, and an increase in any breastfeeding at 6 months postpartum (intervention 75\%, usual care 69\%). ${ }^{6}$ Conducted between 2013 and 2016, participants in the RUBY RCT were first time mothers, recruited after birth, prior to discharge from hospital. Women allocated to the intervention arm of the trial received standard postnatal care and breastfeeding support in hospital and in the community, along with proactive telephone-based support from an allocated peer volunteer, who had themselves breast fed for at least 6 months, and who received 4 hours of training. ${ }^{7} \mathrm{~A}$ total of 230 peer volunteers provided the intervention in the RUBY RCT, supporting on average two mothers each. Volunteer training and experiences have been reported elsewhere and will not be discussed in this paper. ${ }^{89}$ For those allocated to the intervention, the peer calls were scheduled twice in the first week after birth, weekly until 12 weeks postpartum and then 3-4 weekly until 6 months postpartum, with the participant able to contact the peer between scheduled calls. The calls focused on the mother's breastfeeding experience as well as mother and infant well-being, with peers referring mothers to additional services as needed. More detail is available in the study protocol. ${ }^{7}$

Proactive telephone support, provided by women who have themselves breastfed for at least 6 months, is an intervention that is potentially well suited for scale-up in many countries, with pre-existing consumer-led breastfeeding associations a possible base for such an intervention. Most of these organisations currently require women to actively seek the support themselves. While this may be of great benefit to the many women who actively engage with these organisations, it is not necessarily the best option for women who wish to breastfeed but are less motivated or have lower self-efficacy. Women whose infants are likely to benefit the most from breastfeeding support are the least likely to access it. ${ }^{5}{ }^{10}$ It is for these reasons the proactive telephone support model is potentially a powerful and scalable intervention at a population level.

It is imperative for organisations implementing a proactive peer support intervention for breastfeeding to understand the consumer experience to ensure programmes are acceptable, accessible, responsive and provide improved outcomes. ${ }^{11}$ The current literature describing mothers' experiences of proactive breastfeeding support programmes is mainly limited to a few relatively small studies in Sweden ${ }^{12}$ (proactive, telephone-based professional support), the $\mathrm{UK}^{13-16}$ (predominantly face to face peer support models) and Australia ${ }^{17} 18$ (mixture of peer/professional support face to face). Dennis ${ }^{19}{ }^{20}$ Canadian study of the effect of proactive telephone-based peer support on breastfeeding, on which the RUBY study was based, reports maternal experiences including high rates of overall satisfaction and satisfaction with 'enough peer contact to help them with breast feeding'. Given the paucity of the literature reporting how, and what women experience in a proactive telephone-based peer support model, this cross-sectional study aimed to explore women's experiences of receiving the RUBY peer support intervention.

\section{Rationale}

This nested sub-study of the larger RUBY RCT aimed to evaluate the interventions from the participant perspective, a secondary aim of the RUBY trial. ${ }^{7}$ In a model of proactive telephone-based peer support, which produced positive breastfeeding outcomes, it is important to understand how, and what, supportive interactions the participants experienced and their views of this support. These perspectives can inform the frameworks and development, of future peer support programmes.

\section{METHODS}

\section{Study design}

All women in the intervention arm of the RUBY RCT who completed the 6-month telephone interview were invited to complete a postal survey (online supplemental appendix), which was specifically designed to explore their experiences of receiving peer support.

\section{Patient public involvement}

Representatives of the Australian Breastfeeding Association (https://www.breastfeeding.asn.au/), the largest breastfeeding advocacy group in Australia, were members of the RUBY research team and were involved in the design of the survey and training of the peer volunteers.

\section{Data collection}

Data collection for the RUBY study occurred at three time points; face to face at recruitment, by telephone at 6 months post birth and by postal survey (intervention group only) following the 6 -month interview. ${ }^{7}$ Participant characteristics, breastfeeding intention, mothers' perceptions of family views of her breastfeeding plans, and perceived level of family and friends support for breastfeeding were collected at recruitment. Infantfeeding outcomes were collected at the 6-month interview. Women allocated to the intervention $(n=574)$, and who completed the 6 -month interview $(n=501)$, were sent a postal survey between August 2013 and March 2016, which explored their views and experiences of telephone support. Following the initial postal survey invitation, a reminder letter and a second invitation to complete the postal survey were sent to non-responders at 3 and 6 weeks, respectively. 
Women were asked to respond to a series of questions regarding the frequency and average length of the calls from their peer, the period over which the support was received, other type of contact with their peer and topics discussed during the calls. Participants were also asked to describe how helpful they found the calls on a five-point Likert-type Scale, where 1='not at all helpful' and $5=$ 'very helpful'. After the surveys had been sent to 263 women, it was decided to add a validated tool ('Peer Support Evaluation Inventory ${ }^{21}$ (PSEI)) to the subsequent surveys, to gain a broader understanding of why the peer support may have been helpful (if it was). Of the 238 women sent surveys after the inclusion of the PSEI, 152 responded. The PSEI was chosen as being a good fit; however, following ethics review and advice, in order to minimise respondent burden, it was decided that only three of the original four most relevant subscales of the PSEI would be used. The instructions for the PSEI specifically state that each subscale of the PSEI can be used independently. We, therefore, chose to use: mother's perceptions of supportive interactions, maternal satisfaction with support received and maternal perceptions of relationship qualities. We did not include maternal perceptions of perceived benefits. The self-report tool invites participants to respond to a series of statements to evaluate the mother's perceptions of supportive interactions, relationship qualities and satisfaction with the support experience using a five-point Likert-type Scale from $1=$ 'strongly disagree' to $5=$ ='strongly agree'.

\section{Data analysis}

Survey responses were entered onto REDCap (Research and Electronic Data Capture) and downloaded to Stata Statistical Software V.14 (Statacorp, 2015) for data cleaning and analysis. Participant characteristics, breastfeeding plans and perception of support for breast feeding were analysed using descriptive statistics, frequencies, percentages and comparisons between groups examined using Pearson's $\chi^{2}$ to compare categorical variables and t-tests for continuous variables. The responses to the PSEI were dichotomised into 'agree' (score 4='agree' or $5=$ ='strongly agree') or 'disagree' (score $1=$ 'strongly disagree' to $3=$ 'unsure') and subsequently analysed using frequencies and percentages.

Content analysis was used for open ended, short answer responses to questions about positive and negative aspects of calls, with codes derived from the text and organised into categories and then themes. ${ }^{22}$ Codes were read and discussed between research team members F McLardieHore (FMcL) and D Forster (DF), with categories and themes developed and agreed on.

Longer open-ended responses were thematically coded using the Attride-Stirling analytic tool ${ }^{23}$ with basic themes systematically abstracted from the data and grouped into similar categories (organising themes). Inductive analysis of these organising themes provides greater understanding of the overall meaning of the data through the development of global themes. The basic, organising and global themes were discussed between research team members FMcL and H McLachlan (HMcL) at each stage and consensus reached. Direct quotes from participants were used to illustrate the themes, with quotes contextualised by participant identification number, age, length of breast feeding (bf) in months, length of peer support (ps) in months and country of birth.

\section{RESULTS}

\section{Participants}

In total, 360 of the 501 (72\%) women sent a postal survey responded. Of these, 341 stated that they had received calls from a peer, while 19 women stated they did not receive the calls and subsequently did not complete any further responses. These 19 women are, therefore, included in table 1 only. Table 1 describes the characteristics of both respondents and non-respondents to the postal survey, including women's perceptions of breastfeeding support from family and friends. Over half the participants were born in Australia, with most speaking English as a first language. Of those born overseas, China, India and the UK were the most frequently reported country of origin, with 48 other countries of birth reported. At recruitment, women were asked to rate the level of breastfeeding support they perceived they had from family and friends, with the majority of participants responding, 'a lot of support' (73\%).

Women who did not respond to the survey were younger, less likely than respondents to be married or live with a partner, have completed a degree or higher, have English as their first language, more likely to have a pension or benefit as their main income, have a low income, be born overseas, and have smoked pre pregnancy. Their infants were more likely to be lower gestation, have received infant formula prior to recruitment and less likely to be receiving any breast milk, or only breast milk, at 6 months (table 1).

\section{Peer support contacts}

Of the 360 returned surveys, 341 (95\%) participants reported receiving one or more contact/s from their peer. Table 2 shows the peer support contact frequency and duration reported by participants.

Over half the women (56\%) received weekly calls from their peer in the first 3 months after birth, as per the planned schedule of calls, with $17 \%$ receiving less frequent calls and 20\% reporting the call frequency varied. Between 3 and 6 months, $42 \%$ of women received calls second weekly or more often, $27 \%$ received monthly calls and $33 \%$ reported calls varied. Most $(85 \%)$ reported the frequency of calls was 'about right', with only 5\% reporting they were 'not often enough'. Approximately one-third of women reported that the length of calls was 6-10 min on average, and another third reported they were 11-20 min. Asked 'when did the calls from the volunteers stop?' over half the women reported ceasing prior to 26 weeks, 32\% stated at 26 weeks (as per the intervention schedule) and 14\% reported after 26 weeks. In terms of who decided to stop the calls, $38 \%$ of women 'agreed 
Table 1 Participant characteristics at recruitment to RUBY RCT

\begin{tabular}{|c|c|c|c|}
\hline Characteristics & $\begin{array}{l}\text { Respondents } \\
\left(\mathrm{n}=360^{\star}\right)\end{array}$ & $\begin{array}{l}\text { Non-respondents } \\
(\mathrm{n}=141)\end{array}$ & $P$ value \\
\hline \multirow[t]{2}{*}{ Maternal age at recruitment to RCT (years) mean (SD) } & 31.9 (4.6 (SD)) & $29.2(5.4(\mathrm{SD}))$ & $<0.001$ \\
\hline & $\mathrm{n} \%$ & n \% & \\
\hline Married or living with partner & 349 (96.9) & $130(92.2)$ & 0.02 \\
\hline Education level graduate degree or higher & $256(71.3)$ & $71(50.4)$ & $<0.001$ \\
\hline Household weekly income pre-tax (\$AUD) & & & $<0.001$ \\
\hline Less than $\$ 1400$ & $83(23.0)$ & $65(46.1)$ & \\
\hline$\$ A 1400$ or more & $243(67.5)$ & $52(36.1)$ & \\
\hline Declined to answer & $34(9.4)$ & $24(17.0)$ & \\
\hline Pension or benefit $n=359$ & $10(2.8)$ & $20(14.2)$ & $<0.001$ \\
\hline Born in Australia & $192(53.3)$ & $56(39.7)$ & $<0.006$ \\
\hline English as first language & $245(68.1)$ & $70(49.7)$ & $<0.001$ \\
\hline Smoked pre pregnancy & $37(10.2)$ & $28(19.9)$ & 0.01 \\
\hline Caesarean birth & $95(26.4)$ & $47(33.3)$ & 0.12 \\
\hline Baby gestation at birth (weeks) mean (SD) & $39.6(1.2(\mathrm{SD}))$ & $39.3(1.1(\mathrm{SD}))$ & 0.01 \\
\hline Birth weight (grams) mean (SD) & $3401.7(445.7$ (SD)) & $3367.4(459.9(\mathrm{SD}))$ & 0.44 \\
\hline Baby admitted to neonatal/special care nursery & $24(6.7)$ & $6(4.3)$ & 0.31 \\
\hline Baby had formula since birth, prior to recruitment to RUBY RCT & $62(17.2)$ & $40(28.4)$ & 0.005 \\
\hline Plans to breast feed 6 months or more & $281(78.1)$ & $113(80.1)$ & 0.19 \\
\hline Level of breastfeeding support from family and friends & & & 0.81 \\
\hline No support & $4(1.1)$ & $3(2.1)$ & \\
\hline A little support & $33(9.2)$ & $14(9.9)$ & \\
\hline Moderate support & $62(17.2)$ & $22(15.6)$ & \\
\hline A lot of support & $261(72.5)$ & $105(74.5)$ & \\
\hline \multicolumn{4}{|l|}{ Breastfeeding outcomes at 6-month interview } \\
\hline Any breast milk & $293(81.4)$ & $83(58.7)$ & $<0.001$ \\
\hline Only breast milk (may include solids) & $216(60.0)$ & $52(36.9)$ & $<0.001$ \\
\hline
\end{tabular}

*Includes 19 participants who returned survey but did not receive ongoing calls. $\mathrm{RCT}$, randomised controlled trial; RUBY, ringing up about breastfeeding early.

together' with the peer, $22 \%$ stated the 'peer decided' and $19 \%$ said 'I decided'.

\section{Other contact with their peer}

Approximately $40 \%$ of respondents had called their peer (reactive contact) between the scheduled calls, and 63\% made contact in other ways, mostly by text message. When asked the reasons for initiating contact, participant's responses included 'returning or rescheduling a call' $(\mathrm{n}=113 / 213,53 \%)$, for 'breastfeeding advice' $(\mathrm{n}=58 / 213$, $27 \%)$ or to 'touch base and update progress' ( $\mathrm{n}=35 / 213$, $16 \%)$. Responding to how many contacts they initiated, most commonly women initiated only one or two contacts themselves.

\section{Topics discussed with peer volunteer}

Participants were asked 'what things did you talk about with the volunteer mother?', selecting from a number of prespecified topics. 'Milk supply' (76\%) was the most frequent response, with 'baby behaviour' (74\%) and 'baby attaching to the breast' (72\%) the next most frequent (table 3).

\section{Positive and negative aspects of calls}

Women were asked how helpful they would describe the telephone support they received overall, on a scale of ' 1 ' (not at all helpful) to ' 5 ' (very helpful), and $79 \%$ ( $\mathrm{n}=261 / 330)$ of participants responded 'helpful' to 'very helpful', 12\% responded ' 3 ' and 9\% '1-2' (not helpful). Asked to respond to the question 'did you find anything particularly positive (helpful) about these calls?' $87 \%$ ( $n=286 / 328)$ of participants responded 'yes'. Further to this, 279 completed an open-ended response to describe what was positive. Content analysis was undertaken. Themes included having another mother knowing what she was going through (23\%), receiving advice and guidance $(15 \%)$, reassurance $(13 \%)$ and that the peers were friendly and easy to talk to (13\%). 
Table 2 Frequency and duration of contact with peer volunteer

n (\%)

On average how often did you receive calls from your volunteer in the first 3 months? $n=341$

$\begin{array}{lc}\text { Twice weekly } & 22(6.5) \\ \text { Weekly } & 192(56.3) \\ \text { 2nd weekly } & 53(15.5) \\ \text { Monthly } & 5(1.5) \\ \text { It varied } & 69(20.3)\end{array}$

On average how often did you receive calls from your volunteer after the first 3 months? $n=331$

$\begin{array}{lc}\text { Twice weekly } & 8(2.5) \\ \text { Weekly } & 38(11.6) \\ \text { 2nd weekly } & 90(27.5) \\ \text { Monthly } & 87(26.6) \\ \text { It varied } & 108(32.5)\end{array}$

How did you feel about the frequency of calls you received? $\mathrm{n}=332$

\begin{tabular}{lr} 
About right & $283(85.3)$ \\
Too often & $33(9.9)$ \\
$\begin{array}{ll}\text { Not often enough (I would have liked more } \\
\text { calls) }\end{array}$ & $16(4.8)$ \\
\hline
\end{tabular}

On average how long did these calls last? $n=332$

0-5 min

$43(13.0)$

6-10 $\mathrm{min}$

$105(31.6)$

$11-20 \mathrm{~min}$

$108(32.5)$

Longer than $20 \mathrm{~min}$

$44(13.3)$

It varied

$32(9.6)$

When did the calls from your volunteer stop (in weeks)? $n=317$

$\begin{array}{lc}1 & 2(0.6) \\ 2-4 & 27(8.5) \\ 5-8 & 28(8.8) \\ 9-12 \text { weeks } & 15(4.7) \\ 13-16 \text { weeks } & 35(11.0) \\ 17-20 \text { weeks } & 30(9.5) \\ 21-25 \text { weeks } & 35(11.0) \\ 26 & 100(31.5) \\ \text { Greater than } 26 \text { weeks } & 45(14.2) \\ \text { If the calls stopped who decided to stop the calls? } \mathrm{n}=295 \\ \text { We agreed together } & 111(37.6) \\ \text { Volunteer decided } & 64(21.7) \\ \text { I decided } & 57(19.3) \\ \text { Do not remember } & 48(16.3) \\ \text { Other } & 15(5.1) \\ \text { Did you ever call the volunteer yourself? } \mathrm{n}=335 & \\ \text { Yes } & 137(40.9)\end{array}$

Did you ever contact the volunteer yourself in another way? $\mathrm{n}=341$

Yes 215 (63.0)

Table 2 Continued

n (\%)

Other type of contact $n=215$

Text message (short message service)

201 (93.4)

Email 12 (5.6)

Other (eg, Facebook, WhatsApp, WeChat, 12 (5.6)

Post)

If you contacted your volunteer, can you recall the number of times? $n=188$

\begin{tabular}{lc}
1 & $38(20.4)$ \\
2 & $54(29.0)$ \\
3 & $30(16.1)$ \\
4 & $8(4.3)$ \\
5 & $30(16.1)$ \\
$6-20$ & $26(14.1)$ \\
\hline
\end{tabular}

Women were also asked to respond to 'did you find anything negative (not helpful) about these calls?' and $15 \%(n=48 / 331)$ responded 'yes'. Content analysis of these responses included there was limited advice (17\%), difficulty finding time for the call $(15 \%)$ and nothing to talk about (15\%).

\section{Peer Support Evaluation Inventory}

The three subscales of the PSEI ${ }^{21}$ were used to further understand the mothers' experience of support included 'mother's perceptions of supportive interactions', 'maternal satisfaction with support received' and 'maternal perceptions of relationship qualities', with statements grouped under common domains (table 4).

Responses to statements regarding the mother's perceptions of the support from their peer are grouped

Table 3 Topics discussed with peer volunteer

\section{What things did you talk about with your peer}

Milk supply

n (\%)

Baby behaviour

259 (76.0)

Baby attaching to the breast

251 (73.6)

Reassured me

$246(72.1)$

Nipple or breast pain

$245(71.9)$

Advised me where to get help

$211(61.9)$

Lack of sleep

$207(60.7)$

How often to feed my baby

$195(57.2)$

Baby sleep/wake patterns

$190(55.7)$

Gave me emotional support

$187(54.8)$

Settling my baby

$185(54.3)$

Baby care

161 (47.2)

My emotional well-being

$161(47.2)$

Support from my family

$145(42.5)$

$124(36.4)$

Other

Continued 
Table 4 Peer Support Evaluation Inventory

\section{Maternal perceptions of supportive interactions}

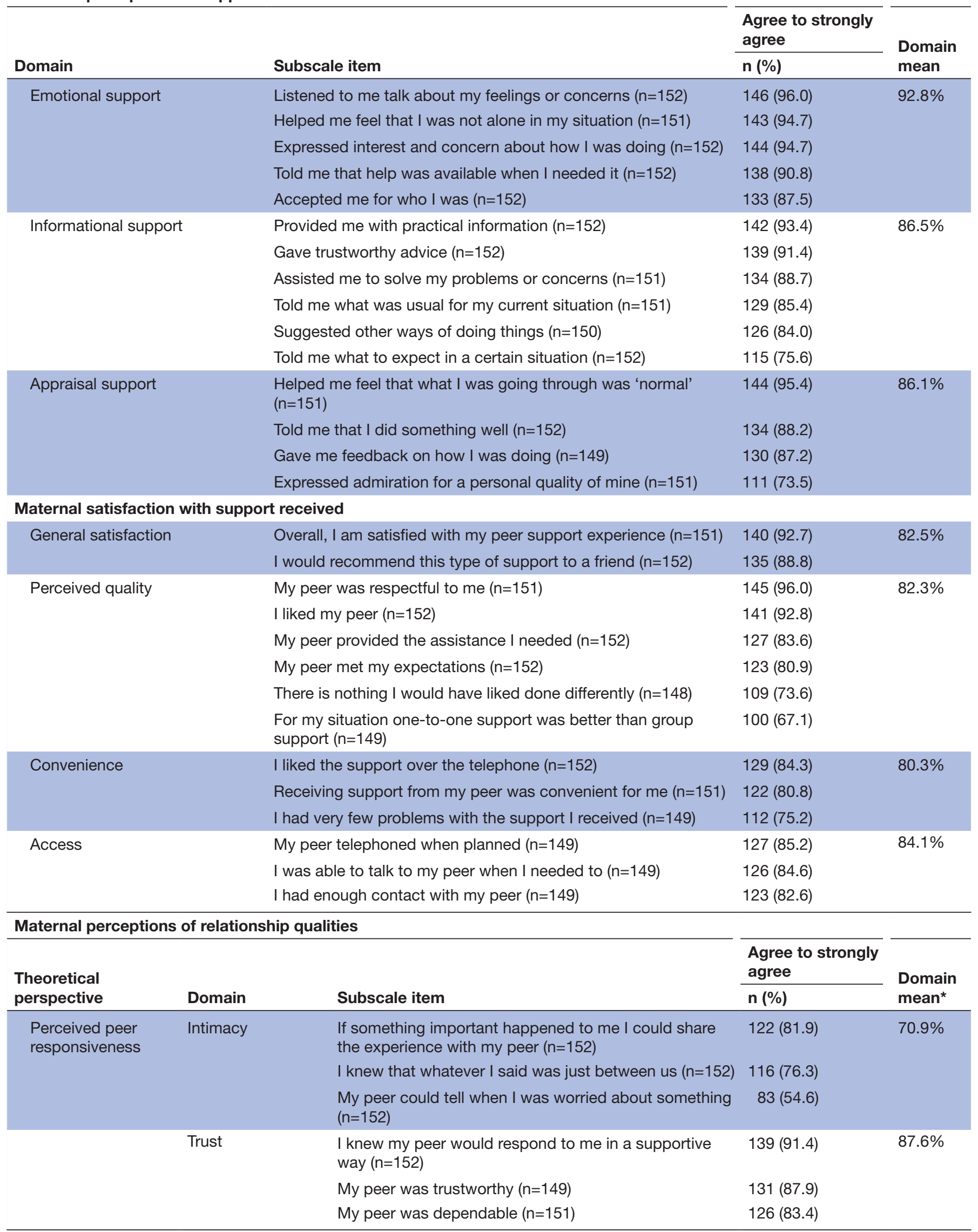


Table 4 Continued

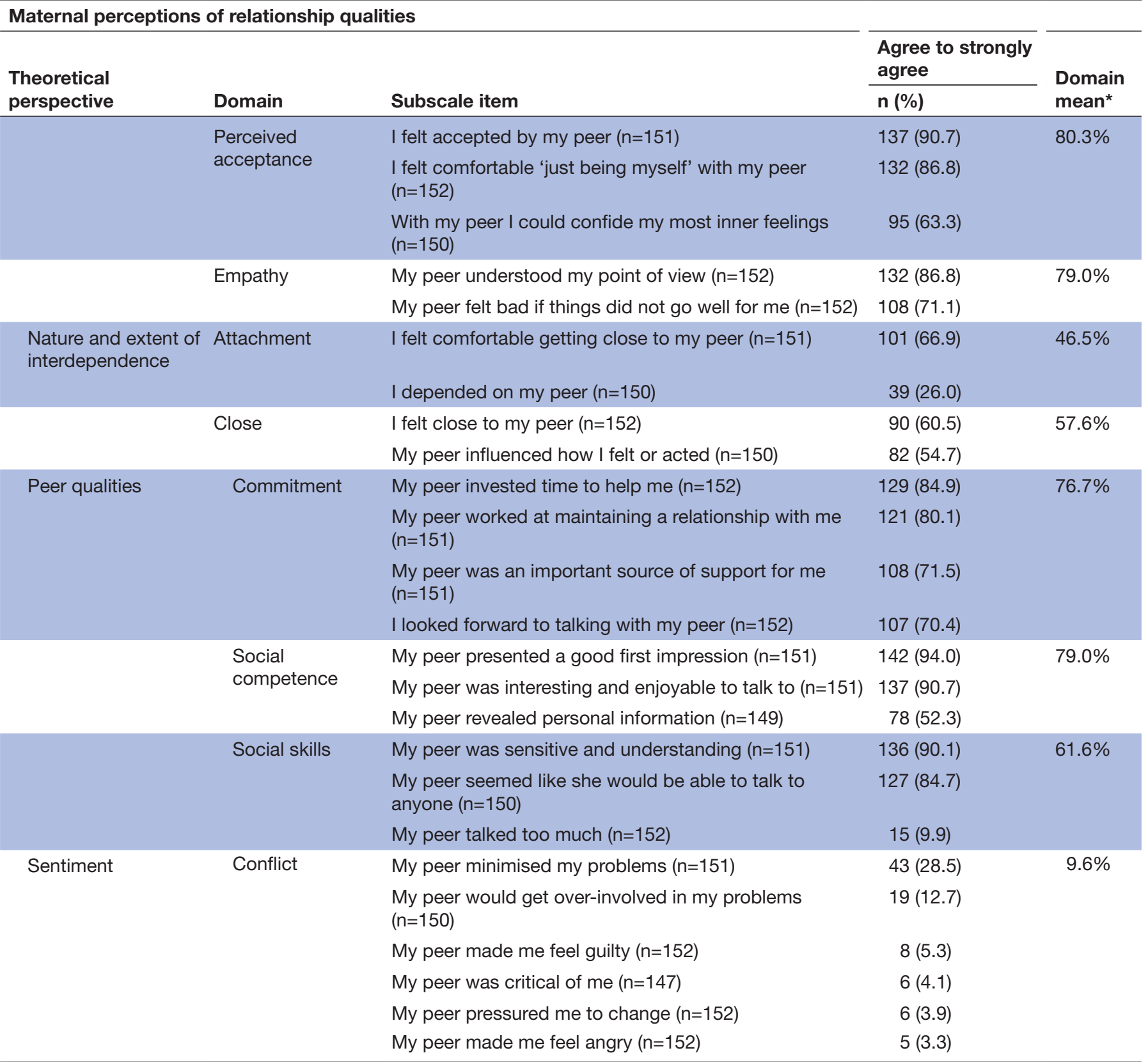

*Means calculated for the scale 'perceptions of relationship qualities' should be viewed in the context that some domains contained items which could be interpreted differently (positively or negatively) for example, 'I depended on my peer' maybe be viewed as positive by some, but not others, thus an overall mean may not clearly indicate participant perceptions, thus we considered it inappropriate to reverse score these items.

as either emotional, informational or appraisal supportive interactions, according to three peer support domains. ${ }^{24}$ Of these domains, 'emotional' support received the most positive responses, with a mean of $93 \%$ agreeing with these statements. Responding to 'satisfaction with support' statements under the general domain, the majority of participants perceived their peer support experience as satisfactory overall $(93 \%)$ and that they would recommend the type of support to a friend (89\%). Participants also responded positively to the domains of perceived quality, in particular the statement 'my peer was respectful to me'. Perceptions of their peer relationship were also explored with statements under the theoretical perspectives of 'perceived peer responsiveness' with participants responding most positively to statements in the domains of trust, and perceived acceptance.

Less frequently endorsed were the domains of attachment and close, and the six statements within the conflict domain were infrequently agreed on, with four of the statements (my peer).... 'pressured me to change', 'made me feel guilty', 'made me feel angry' and 'was critical of me' being endorsed by less than $6 \%$ of respondents. 


\section{Would mothers recommend this support to others?}

Women were asked if they would recommend this type of support to other new mothers, with 97\%, $(n=320 / 331)$ responding 'yes'. They were given an opportunity to describe their response further, and 221 commented. Two global themes emerged from these responses. The first 'yes, absolutely' contained organisational themes of 'empathetic, reassuring, non-judgemental support', 'more than just breastfeeding support' and 'an easy way to be supported'. The second global theme of yes, but....' contained organisational themes of 'recommend for those early days' and 'particularly for those who are isolated'. These themes are discussed further below.

\section{'Yes, absolutely'}

The greatest response to this question was that women said 'yes, absolutely' they would recommend this support.

\section{Empathetic, reassuring and non-judgemental support}

Women valued that their peer was an experienced mother who understood what they 'were going through' and was able to use this experience to support them. They appreciated that the peer provided a safe place to talk, someone outside their family and circle of friends who was unbiased and non-judgemental and was 'just for them'. Peers were sensitive, caring, empathetic, and were someone who would listen, they could talk to and ask questions.

Everyone throws their opinions and advice at you as a firsttime mother so it's really refreshing to have someone impartial to your family and friends circle to ask all the questions under the sun that you may (and do!!) have! (\#1444, 38 yrs. bf-6mths, ps-5.5mths, England).

As a new mum in that first few weeks, it can be a particularly overwhelming experience. I found it comforting to know that there was an unbiased support just a phone call away, and when it got too difficult it was nice to have someone call in to check on you. (\#1523, 36 yrs. bf-6mths, ps-4.5mths, Malaysia).

It's good to speak to someone that has been through it before and understands the obstacles you are going through. (\#3139, 25 yrs. bf-6mths, ps-6mths, Australia).

\section{More than just breastfeeding support}

Peers provided advice and guidance, not only on breastfeeding matters, but also on many other issues faced in the new mother's transition to parenthood and referred mothers to professional help as needed. As well as providing practical support the peers offered emotional support, reassurance, encouragement, affirmation and helped to normalise the new mother's experiences. The peer 'checking in', as well as being available for them to call, made the mothers feel secure and as though they were 'not alone'.

I think this type of support is fantastic. As a new mother having someone to ask questions and receive advice from is $\mathrm{cru}$ cial. Those first few weeks can be very hard finding positions to feed, helping soreness, wondering if what's happening to you is normal and to have that support was great. (\#1204 27 yrs. bf-6mths, ps-3mths, Australia).

...it is useful to have someone in your corner without an agenda who can listen to your own experience. (\#1754 31 yrs. bf-6mths, ps-4mths, Australia).

An easy way to be supported

The telephone was a quick and easy way for women to receive support, and the proactive nature of the calls made women feel like they didn't need to 'make an effort'. Women appreciated when the peer was flexible with the call schedule (frequency and time of day), with contact being made according to the individual needs of the mother. Women also liked the continuity of the support, as they enjoyed getting to know their peer, and did not need to explain their story each time.

It was easier over the phone as we connect (sic) rather quickly and start to know each other personally and her kind words of encouragement helped me through..." (\#3079 28 yrs. bf6mths, ps-6mths, Australia).

'Yes, but....'

A number of respondents said they would recommend the support but qualified the response by suggesting that the support would be best for certain groups of women.

Recommend for those early days particularly for isolated mothers Many women felt the support was particularly vital in the early days of motherhood, for first time mothers, and that women who were isolated and had little family support would benefit the most.

.... those first few weeks, seems like a lifetime, it helps with the overwhelm (sic) and isolation I felt, and gave me a sense of certainty amidst the chaos. I really looked forward to our chats. I often contacted her. (\#1249 31 yrs. bf-6mths, ps3mths, Australia).

... especially helpful to new mothers who are new immigrants, it can make people feel like (they are) connected to the society and other people care about you. (\#2038 29 yrs. bf-6mths, ps-6mths, China).

... when you're really isolated... it was really nice feeling that someone cared how I was getting on, as all my family live interstate. (\#1145 33 yrs. bf-6mths, ps-6mths, Australia).

A small number of women were not sure if they would recommend the support, explaining that they experienced difficulties in finding time for the phone calls in this busy time with a new baby, while others felt information from a non-professional was lacking.

\section{Further comments}

Participants were invited to make any further comments about the support, or the RUBY RCT itself, with $96 \%$, $(n=326 / 341)$ commenting. Many women expressed their overwhelming gratitude for being a part of RUBY and for the help and support provided by their peer. Analysis of these responses revealed the same themes of "empathetic, 
reassuring non-judgemental support', 'more than just breastfeeding support' and 'an easy way to be supported' as previously described.

In addition, a new theme that emerged was 'she helped and inspired me to become a proud, confident mother'. Mothers talked about the peer investing their time, and through sharing their experiences, the peer helped the mother to cope, 'keep going', trust her instincts and be proud of herself as a new mother. Many women talked about how they felt empowered, their confidence bolstered by the peer and how they were inspired to create a new breastfeeding goal.

It's been wonderful to share this unique journey with her over the 6 months. Breastfeeding is a passion and commitment that we both feel strongly about and have enjoyed. She helped me to feel proud and confident about breastfeeding. my baby and achieving my goal of breastfeeding for 6-12 months. (\#1395 36 yrs. bf-6mths, ps-5.5mths, Japan).

I would like to thank the volunteer mother for taking the time to help a new mum. This is time taken away from their own families to give support and encouragement to a total stranger... without the support from a volunteer mum I may have stopped breastfeeding in the initial phases when everything felt too hard and overwhelming. (\#1032 40 yrs. bf-6mths, ps-6mths, Zambia).

It was also due to the advice and support from my volunteer mum that I was able to articulate and defend my reasons for exclusively breastfeeding until 6 months, my hope to breastfeed my daughter until at least 24 months, to be able to breastfeed in public. (\#1070 33 yrs. bf-6mths, ps-6mths, New Zealand).

A small number of women stated that this type of support was not suited to them, mainly due to difficulties establishing contact and coordinating calls during the busy early days, or some feeling that the calls added to their stress as a new mother.

\section{DISCUSSION}

This paper provides insight into the views and experiences of first-time mothers' receiving proactive telephone peer support for breastfeeding, in the context of an RCT in which the intervention tested increased breastfeeding. While perceiving high levels of breastfeeding support from family and friends, women still valued the support from the peers, reporting high levels of helpfulness and overall satisfaction with the support. Women viewed their experiences as positive and felt the responsive support helped them to manage the many challenges faced in their transition to motherhood. Peers shared their experiential knowledge and provided realistic, practical advice, information and guidance on issues such as breast milk supply, attachment and nipple pain, but also assured the mothers that much of their experience was 'normal', and similar to what others had 'gone through', which women found affirming and helped them to 'cope'.
Findings reinforce evidence that women view the support as beyond simply breastfeeding support, providing reassurance and empowerment ${ }^{14} 25$ increasing their confidence $^{26}$ and reducing their feelings of isolation. ${ }^{24}$

Similar to the findings reported by McInnes and Chambers ${ }^{27}$ mothers valued an avenue to ask questions and someone to listen to them without judgement, someone accepting of them and someone with personal experience who understood what they were going through. In this study women described the peers as friendly, caring, understanding and accepting. Having a single peer providing support was important to the mothers, as they built a trusting relationship over the period of contact, with many women feeling comfortable enough to contact the peer if needed, yet most did not report feeling dependent on their peer. In the 2010 study of peer support for postpartum depression, Dennis ${ }^{24}$ suggested a lack of dependence was associated with women who did not need extra support, or who only needed it for a short period of time; however, in this study many women expressed that they felt inspired, gained confidence and were proud of themselves as a mother, and thus a lack of dependence on the peer, might be seen as an expression of empowerment.

Many women expressed the encouragement and support from their peer helped them to cope and 'keep going', during difficult times. Triggers for breastfeeding cessation do not always stem from issues with feeding techniques or problems with breastfeeding itself, but instead can evolve from emotional or social triggers. ${ }^{28}$ When challenges arise, many women feel that making changes, such as reducing, or even ceasing breastfeeding is one of the few resources within their control that can bring about family well-being. ${ }^{29}$ The high levels of emotional, as well as appraisal support reported by the mothers in this study may have acted as a buffer to their stressors, ${ }^{21}$ assisting them to continue breastfeeding.

Women found the support convenient and accessible, with the schedule of calls, most frequent in the early weeks and months and less so from three to 6 months, considered 'about right', while allowing for schedule flexibility. They appreciated the proactive nature of the support and the additional ability to access their peer when they wanted. Less than half of the participants made reactive contacts, and most only once or twice, with this contact mostly through text message. Similar to findings of a recent UK study, the use of text messages was viewed positively by women. ${ }^{30}$ Less than a third of respondents were supported for the full 6 months, with the decision to cease the support most frequently made together with the peer, or many mothers deciding themselves. Dennis ${ }^{20}$ reported a third of women did not maintain contact beyond 2 months with their peer, and only $30 \%$ having some contact in the third and final month of support. She, therefore, concluded that a standardised peer support intervention was unnecessary. Similarly, women in this study did not necessarily need the full 6 months of support to gain the benefits, suggesting the length of support should be flexible and tailored to the individual 
needs of each mother. On the other hand, what was tested in the study was support following a suggested call schedule and implementing this intervention did result in increased breast milk feeding at 6 months compared with standard care.

\section{LIMITATIONS OF THIS STUDY}

This study is limited by non-responders being less likely to have been breastfeeding at 6 months, compared with responders, and therefore these women may have been more dissatisfied with their experience.

\section{STRENGTH OF THE STUDY AND FURTHER RECOMMENDATIONS}

This study is strengthened by the large number of participants, the description of the intensity of the support and the use of qualitative data to assess the validity of the quantitative findings in the context of an RCT where the intervention improved breastfeeding rates at 6 months. Rigour was achieved in qualitative data analysis through the involvement of different research team members in development of codes and themes, discussions and reaching consensus. Participant quotes have been used to embody the themes, thus ensuring credibility. If implementing a programme of telephone-based peer support, recommendations should include a regular yet flexible support schedule that can be tailored to suit the individual mother. The use of text messages by peers could be used as complementary to, or occasionally instead of, calls in an effort to establish or maintain contact with mothers who may be finding difficulty making time.

\section{CONCLUSION}

In view of the improved breastfeeding outcomes of women who received the proactive telephone-based peer support in the RUBY RCT, and their positive experiences of receiving the proactive telephone-based peer support, there is evidence to support the scale-up of this model. Providing accessible, proactive support for breastfeeding via telephone is an important resource for women. While women valued the information their peer provided, so too they benefited from the empathy, reassurance and encouragement. Recommendations to enhance and facilitate communication between the peer and the mother, include ensuring flexibility in the scheduling of calls and the use of text messages in conjunction with proactive calls, tailored to meet the individual needs of the mother.

Acknowledgements The authors thank the women who participated in the study, the peer supporters and the research staff.

Contributors All authors were involved with the design of the study and the data collection tool. FMcL was responsible for the collection of the data. All authors had full access to all the data, were responsible for the integrity of the data and were involved in the analysis and interpretation of the data. FMcL took the lead in writing the manuscript with DAF, HMcL and TS providing critical feedback and editing to the final version of the manuscript.
Funding This work was supported by philanthropic funding from the Felton Bequest, grant number CT 13442, and La Trobe University.

Competing interests None declared.

Patient consent for publication Not required.

Ethics approval This study obtained ethics approval from La Trobe University (HEC 12-082), Royal Women's Hospital (HREC 12/25), Monash Medical Centre (HREC 12251B) and Western Health (HREC/12/WH/107). Women who chose to participate provided written consent as part of the Ringing Up about Breastfeeding earlY randomised controlled trial.

Provenance and peer review Not commissioned; externally peer reviewed.

Data availability statement All data relevant to the study are included in the article or uploaded as supplementary information. All data relevant to the study are included in the article.

Supplemental material This content has been supplied by the author(s). It has not been vetted by BMJ Publishing Group Limited (BMJ) and may not have been peer-reviewed. Any opinions or recommendations discussed are solely those of the author(s) and are not endorsed by BMJ. BMJ disclaims all liability and responsibility arising from any reliance placed on the content. Where the content includes any translated material, BMJ does not warrant the accuracy and reliability of the translations (including but not limited to local regulations, clinical guidelines, terminology, drug names and drug dosages), and is not responsible for any error and/or omissions arising from translation and adaptation or otherwise.

Open access This is an open access article distributed in accordance with the Creative Commons Attribution Non Commercial (CC BY-NC 4.0) license, which permits others to distribute, remix, adapt, build upon this work non-commercially, and license their derivative works on different terms, provided the original work is properly cited, appropriate credit is given, any changes made indicated, and the use is non-commercial. See: http://creativecommons.org/licenses/by-nc/4.0/.

\section{ORCID iDs}

Fiona E McLardie-Hore http://orcid.org/0000-0001-7434-4154

Helen L McLachlan http://orcid.org/0000-0001-5101-9842

Touran Shafiei http://orcid.org/0000-0002-7363-0519

Della A Forster http://orcid.org/0000-0002-6083-087X

\section{REFERENCES}

1 Rollins NC, Bhandari N, Hajeebhoy N, et al. Why invest, and what it will take to improve breastfeeding practices? Lancet 2016;387:491-504

2 Victora CG, Bahl R, Barros AJD, et al. Breastfeeding in the 21st century: epidemiology, mechanisms, and lifelong effect. Lancet 2016;387:475-90.

3 World Health Organization. Global strategy for infant and young child feeding. Geneva: World Health Organization, 2003.

4 United Nations. Transforming our world: the 2030 agenda for sustainable development un General assembly, 2015.

5 McFadden A, Gavine A, Renfrew MJ, et al. Support for healthy breastfeeding mothers with healthy term babies. Cochrane Database Syst Rev 2017;2:CD001141.

6 Forster DA, McLardie-Hore FE, McLachlan HL, et al. Proactive Peer (Mother-to-Mother) Breastfeeding Support by Telephone (Ringing up About Breastfeeding Early [RUBY]): A Multicentre, Unblinded, Randomised Controlled Trial. EClinicalMedicine 2019;8:20-8.

7 Forster DA, McLachlan HL, Davey M-A, et al. Ringing Up about Breastfeeding: a randomised controlled trial exploring early telephone peer support for breastfeeding (RUBY) - trial protocol. BMC Pregnancy Childbirth 2014;14:177.

8 Grimes HA, Shafiei T, McLachlan HL, et al. Volunteers' experiences of providing telephone-based breast-feeding peer support in the ruby randomised controlled trial. Public Health Nutr 2020:1-11.

9 Grimes HA, Forster DA, Shafiei T, et al. Breastfeeding peer support by telephone in the ruby randomised controlled trial: a qualitative exploration of volunteers' experiences. PLoS One 2020;15:e0237190.

10 Amir LH, Donath S. A systematic review of maternal obesity and breastfeeding intention, initiation and duration. BMC Pregnancy Childbirth 2007;7:9.

11 Crawford MJ, Rutter D, Manley C, et al. Systematic review of involving patients in the planning and development of health care. BMJ 2002;325:1263.

12 Ericson J, Flacking R, Udo C. Mothers' experiences of a telephone based breastfeeding support intervention after discharge from 
neonatal intensive care units: a mixed-method study. Int Breastfeed J 2017; $12: 50$.

13 McLeish J, Redshaw M. Peer support during pregnancy and early parenthood: a qualitative study of models and perceptions. BMC Pregnancy Childbirth 2015;15:257.

14 Thomson G, Crossland N, Dykes F. Giving me hope: women's reflections on a breastfeeding peer support service. Matern Child Nutr 2012;8:340-53.

15 Hoddinott P, Lee AJ, Pill R. Effectiveness of a breastfeeding peer coaching intervention in rural Scotland. Birth 2006;33:27-36.

16 Clarke JL, Ingram J, Johnson D, et al. The ABA intervention for improving breastfeeding initiation and continuation: feasibility study results. Matern Child Nutr 2020;16:e12907.

17 Schmied V, Beake S, Sheehan A, et al. Women's perceptions and experiences of breastfeeding support: a metasynthesis. Birth 2011;38:49-60.

18 Kruske S, Schmied V, Sutton I, et al. Mothers' experiences of facilitated peer support groups and individual child health nursing support: a comparative evaluation. J Perinat Educ 2004;13:31-8.

19 Dennis C-L. Breastfeeding peer support: maternal and volunteer perceptions from a randomized controlled trial. Birth 2002;29:169-76.

20 Dennis C-L, Hodnett E, Gallop R, et al. The effect of peer support on breast-feeding duration among primiparous women: a randomized controlled trial. CMAJ 2002;166:21-8.

21 Dennis C-L. The effect of peer support on postpartum depression: a pilot randomized controlled trial. Can J Psychiatry 2003;48:115-24.
22 Erlingsson C, Brysiewicz P. A hands-on guide to doing content analysis. Afr J Emerg Med 2017;7:93-9.

23 Attride-Stirling J. Thematic networks: an analytic tool for qualitative research. Qual Res 2001;1:385-405.

24 Dennis C-L. Postpartum depression peer support: maternal perceptions from a randomized controlled trial. Int $J$ Nurs Stud 2010;47:560-8.

25 Thomson G, Crossland N. Callers' attitudes and experiences of UK breastfeeding helpline support. Int Breastfeed J 2013;8:3.

26 Ingram J. A mixed methods evaluation of peer support in Bristol, UK mothers', midwives' and peer supporters' views and the effects on breastfeeding. BMC Pregnancy Childbirth 2013;13:192.

27 McInnes RJ, Chambers JA. Supporting breastfeeding mothers: qualitative synthesis. J Adv Nurs 2008;62:407-27.

28 Schafer EJ, Buch ED, Campo S, et al. From initiation to cessation: turning points and coping resources in the breastfeeding experience of first-time mothers. Women Health 2019;59:449-63.

29 Hoddinott P, Craig LCA, Britten J, et al. A serial qualitative interview study of infant feeding experiences: idealism meets realism. BMJ Open 2012;2:e000504.

30 Ingram J, Thomson G, Johnson D, et al. Women's and peer supporters' experiences of an assets-based peer support intervention for increasing breastfeeding initiation and continuation: a qualitative study. Health Expect 2020;23:622-31. 